\title{
The risk of colorectal cancer with symptoms at different ages and between the sexes: a case-control study
}

\author{
William Hamilton*1, Robert Lancashire ${ }^{2}$, Debbie Sharp ${ }^{1}$, Tim J Peters ${ }^{1}$, \\ KK Cheng ${ }^{2}$ and Tom Marshall ${ }^{2}$
}

Address: ${ }^{1}$ Academic Unit of Primary Health Care, Department of Community Based Medicine, University of Bristol, 25 Belgrave Road, Bristol, BS8 2AA, UK and 2Department of Public Health and Epidemiology, University of Birmingham, Edgbaston, Birmingham, B15 2TT, UK

Email: William Hamilton* - w.hamilton@bristol.ac.uk; Robert Lancashire - r.j.lancashire@bham.ac.uk;

Debbie Sharp - Debbie.sharp@bristol.ac.uk; Tim J Peters - tim.peters@bristol.ac.uk; KK Cheng - k.k.cheng@bham.ac.uk;

Tom Marshall - T.P.Marshall@bham.ac.uk

* Corresponding author

Published: 17 April 2009

BMC Medicine 2009, 7:17 doi:10.1186/1741-7015-7-17
Received: 6 March 2009

Accepted: 17 April 2009

This article is available from: http://www.biomedcentral.com/l74/-70/5/7/17

(c) 2009 Hamilton et al; licensee BioMed Central Ltd.

This is an Open Access article distributed under the terms of the Creative Commons Attribution License (http://creativecommons.org/licenses/by/2.0), which permits unrestricted use, distribution, and reproduction in any medium, provided the original work is properly cited.

\begin{abstract}
Background: Colorectal cancer is generally diagnosed following a symptomatic presentation to primary care. Although the presenting features of the cancer are well described, the risks they convey are less well known. This study aimed to quantify the risk of cancer for different symptoms, across age groups and in both sexes.
\end{abstract}

Methods: This was a case-control study using pre-existing records in a large electronic primary care database. Cases were patients aged 30 years or older with a diagnosis of colorectal cancer between January $200 \mathrm{I}$ and July 2006, matched to seven controls by age, sex and practice. All features of colorectal cancer recorded in the 2 years before diagnosis were identified. Features independently associated with cancer were identified using multivariable conditional logistic regression, and their risk of cancer quantified.

Results: We identified 5477 cases, with 38,314 age, sex and practice-matched controls. Six symptoms and two abnormal investigations (anaemia and microcytosis) were independently associated with colorectal cancer. The positive predictive values of symptoms were: rectal bleeding, positive predictive value for a male aged $\geq 80$ years $4.5 \%$ ( $95 \%$ confidence interval 3.5 , 5.9); change in bowel habit $3.9 \%(2.8,5.5)$; weight loss $0.8 \%(0.5,1.3)$; abdominal pain $1.2 \%(1.0$, I.4); diarrhoea $1.2 \%(1.0,1.5)$ and constipation $0.7 \%(0.6,0.8)$. Positive predictive values were lower in females and younger patients. Only $27 \%$ of patients had reported either of the two higher risk symptoms.

Conclusion: Most symptomatic colorectal cancers present with only a low-risk symptom. There is a need to find a method of identifying those at highest risk of cancer from the large number presenting with such symptoms. 


\section{Background}

Over 35,000 colorectal cancers were diagnosed in England in 2004 [1]. Survival in the UK is worse than in other European countries and the US, partly because of later presentation in the UK [2]. Delays in presentation to medical care and diagnosis have been observed in several studies [3].

Early diagnosis may reduce mortality. The relative risk of death from colorectal cancer is between 0.67 and 0.85 following faecal occult blood screening [4]. A large UK prospective study of screening in half a million patients aged 50 to 69 years found $2 \%$ to be faecal occult blood (FOB) positive, of whom $11 \%$ had colorectal cancer [5]. In 2006, a UK national screening programme was introduced using FOBs in people aged 60 to 69 years [6]. However, only around a quarter of colorectal cancers are likely to be detected in such a screening programme, because most become symptomatic after this age, the sensitivity of the test is only $60 \%$, and almost half of eligible patients decline screening $[5,7]$. Thus, most colorectal cancers will continue to present with symptoms $[8,9]$.

General practitioners (GPs) gain relatively little experience in the diagnosis of colorectal cancer because the incidence is about one per GP per year, and only a proportion of these are diagnosed in primary care [10]. In addition, the relevant symptoms occur frequently in association with benign conditions, which are also much more common. At least half of colorectal cancers only manifest lowrisk symptoms such as constipation or abdominal pain, and there is no intermediate test to identify those particularly likely to harbour cancer (unlike, for example, a chest $\mathrm{X}$-ray in possible lung cancer). Moreover, the main diagnostic test for suspected colorectal cancer is colonoscopy, with a small but important complication rate.

The UK Referral Guidelines for Suspected Cancer [11], which were updated in 2005, have a weak evidence base, concentrate on typical presentations of cancer and may even delay diagnosis in patients with atypical presentations [12]. Since publication of these guidelines, several studies have reported risk estimates for the common symptoms of colorectal cancer when presented to primary care. Rectal bleeding studies reported positive predictive values (PPVs) ranging from $2 \%$ to $6 \%$ [13-16]. Other studies have examined change in bowel habit [14], anaemia $[14,17]$, abdominal pain and loss of weight [15].

However, few studies have examined the effect of age or sex. One calculated a steep increase in PPVs for rectal bleeding and change in bowel habit with age, in parallel with the increasing incidence of colorectal cancer [14]. Others showed a smaller rise [15] or almost none [18]. Males had higher PPVs for most clinical features, reflect- ing the higher incidence in men. Differences with age and sex are important; current guidance for referral ignores age (other than setting a minimum age of 60 years for referral with rectal bleeding or motility symptoms, and 40 years when both are present) and sex (apart from a lower threshold haemoglobin value for women). Most other countries have no specific guidance for identification of symptomatic colorectal cancer, although screening is recommended generally from the age of 50. We therefore studied the symptoms of colorectal cancer in a large electronic dataset to calculate risk estimates in narrow age bands and in both sexes.

\section{Methods}

Data were provided by The Health Improvement Network (THIN), a database of electronic medical records uploaded from general practices using the VISION computer system. It is an offshoot of the General Practice Research Database (GPRD), restricted to practices within the GPRD using that specific computer technology. The records contain patient characteristics, all prescriptions, consultations, diagnoses and primary care investigations. There are currently 2.2 million active patients in over 300 practices: 4.7 million patients when historical data are included. The THIN database is subject to frequent internal quality checks, with any practices failing to maintain adequate quality standards removed from the database.

\section{Identification of cases and controls}

Cases were patients aged 30 years or older with a diagnosis of colorectal cancer between January 2001 and July 2006 and at least 2 years of full electronic records before diagnosis. Up to seven controls per case were selected (the maximum allowed within THIN regulations), using a computerised random number sequence. Controls were matched for practice, sex and age, but had not had colorectal cancer: they also had at least 2 years of records before the index date (the date of diagnosis of their matched case). The full date of birth was unavailable to protect anonymisation; however, the year of birth was available. Where possible, controls were matched to the same year of birth in years as cases; if no controls in this year were available, they were matched to within 1 year, then 2 years and so on up to a maximum of 5 years. THIN staff identified and provided complete records for all cases and controls.

\section{Definition of variables}

From a review of the literature, 23 candidate variables (features) were identified, either a symptom, or an abnormal primary care investigation, or a predisposing risk marker such as obesity. We also identified codes for irritable bowel syndrome as a potential misdiagnosis. For some symptoms we were also able to take advantage of the availability of data on related prescriptions, for exam- 
ple, prescriptions for antidiarrhoeals and laxatives were obtained as possible surrogates for the relevant symptoms, and similarly antispasmodic drugs for irritable bowel syndrome. Features were designated as new if there were no similar symptoms or prescriptions observed previously in the 2 years before the index date. Haemoglobin values were categorised into $1 \mathrm{~g} / \mathrm{dl}$ bands, and microcytosis defined as a mean red cell volume $\leq 80 \mathrm{fl}$. Weight loss was calculated from the change between the last recorded weight and the highest weight in the previous 2 years, separated into two categories: $\geq 10 \%$ weight loss or $5 \%$ to $10 \%$ weight loss. Patients were assigned to their maximum weight loss category. Obesity was defined as a body mass index $>30 \mathrm{~kg} / \mathrm{m}^{2}$ within 2 years of the index date. Diabetes was considered to be present if it had ever been diagnosed.

\section{Analysis: identification of variables independently associated with cancer}

The main method of analysis was conditional logistic regression. For the variables that also had prescriptions as surrogates, preliminary analyses compared the odds ratio for a prescription without a record of the feature with the odds ratio for the feature itself. As these were similar for all three of this type of variable, constipation, diarrhoea and irritable bowel syndrome, the relevant pairs of variables were merged.

All variables with a univariable association with cancer significant with a $P$ value $<0.1$ were entered into a staged multivariable analysis. The first stage of the multivariable analysis grouped clinically related variables together. These were: intestinal motility features (constipation, diarrhoea, change in bowel habit and flatulence); pain features (irritable bowel syndrome, or prescription of an antispasmodic and abdominal pain); bleeding features (rectal bleeding, anaemia and microcytosis); systemic features (weight loss and thrombo-embolism); obesity features (diabetes and obesity). Only variables with a $P$ value $<0.05$ within their group were considered for the final model.

\section{Analysis: estimation of PPVs}

Age was stratified into four bands: 30 to 59 years (there were too few cancers in this band for meaningful sub-division) and 10-year bands thereafter, up to $80+$ years. For each age/sex/feature combination we created a $2 \times 2$ table and calculated the positive likelihood ratio and its $95 \%$ confidence intervals. We used Bayes' theorem (posterior odds $=$ prior odds $\times$ likelihood ratio) to estimate PPVs [19]. The prior odds were derived from national incidence rates stratified by age and sex for 2003 (the middle year of our cohort), in that an annual incidence of, for example, 5 per 1000, is the equivalent of 199 to 1 odds against having cancer diagnosed in the next year [20]. For males, the annual incidence rates used were: aged 30 to 59 years, $0.026 \%$; 60 to 69 years, $0.19 \%$; 70 to 79 years, $0.35 \%$ and $80+$ years, $0.43 \%$. Female rates for the same age groups were: $0.02 \%, 0.11 \%, 0.21 \%$ and $0.27 \%$.

With the 5000 cases available, there was > 99\% power to detect $5 \%$ having a particular feature, compared with $1 \%$ amongst controls. Such a difference was viewed in advance as being potentially clinically useful, and from a previous primary care study was considered possible [15]. Ethical approval was obtained from the London Multicentre Research Ethics Committee.

\section{Results}

THIN staff identified 5477 cases from 317 practices and were able to match 38,314 controls, with only seven very elderly cases having fewer than seven controls available. 36,925 (96.4\%) controls were matched to the same year of birth, and 1150 (3\%) to the adjoining year, leaving only 239 controls 2 to 5 years different in age. 2911 $(53.1 \%)$ of the cases were male. The median (inter-quartile range) age at diagnosis of cases was 72 years $(63,79)$, with males slightly younger: male median 71 years $(62$, $78)$ and female $73(63,81): P<0.001$, Wilcoxon test. The frequencies of each clinical feature are shown in Table 1. Less than $2.5 \%$ of cases or controls had an abnormal rectal examination ( 15 cases, 2 controls), abdominal masses (86 cases, 19 controls), a positive FOB ( 7 cases, 2 controls), or thrombo-embolism ( 24 cases, 74 controls). These (rare) variables were omitted from further analyses. The final multivariable model is shown in Table 2. PPVs for the six symptoms independently associated with cancer, stratified by age and sex, are shown in Figures 1, 2 and 3, with scales varying for the high, medium and low-risk symptoms, respectively.

\section{Discussion}

This large study shows eight clinical features presenting in primary care to be independently associated with the subsequent diagnosis of cancer. All were previously known, but the precise risk they confer had not been quantified with such precision, nor have they been clearly differentiated across ages and sexes. In general, the PPVs rose with age, particularly after the age of 60 , and were higher in males. However, the absolute risk was relatively low (below 2\%) for all ages and both sexes for constipation, diarrhoea, abdominal pain and loss of weight. Only change in bowel habit (a term that GPs use when the pattern of constipation or diarrhoea is particularly suggestive of colon cancer, or is accompanied by additional symptoms) and rectal bleeding had PPVs of 2\% to 5\% (and these higher PPVs were largely seen in males). 
Table I: Frequency of clinical features in cases and controls.

\begin{tabular}{|c|c|c|c|c|c|}
\hline \multirow[b]{2}{*}{ Clinical feature } & \multicolumn{2}{|c|}{$\begin{array}{c}\text { Cases } \\
(N=5477)\end{array}$} & \multicolumn{2}{|c|}{$\begin{array}{c}\text { Controls } \\
(N=38,3 \mid 4)\end{array}$} & \multirow[t]{2}{*}{$\begin{array}{l}\text { Positive likelihood } \\
\text { ratio }(95 \% \mathrm{Cl})\end{array}$} \\
\hline & $\begin{array}{c}\text { Number with this } \\
\text { feature }\end{array}$ & $\begin{array}{l}\text { Percentage with } \\
\text { this feature }\end{array}$ & $\begin{array}{c}\text { Number with this } \\
\text { feature }\end{array}$ & $\begin{array}{l}\text { Percentage with } \\
\text { this feature }\end{array}$ & \\
\hline \multicolumn{6}{|l|}{ Symptoms } \\
\hline Constipation & 1477 & 27.0 & 4051 & 10.6 & 2.6 (2.4 to 2.7$)$ \\
\hline Diarrhoea & 988 & 18.0 & 2171 & 5.7 & 3.2 (3.0 to 3.4$)$ \\
\hline Change in bowel habit & 615 & 11.2 & 375 & 1.0 & 5.5 (5.2 to 5.8$)$ \\
\hline Rectal bleeding & 853 & 15.6 & 460 & 1.2 & 6.0 (5.7 to 6.3$)$ \\
\hline \multicolumn{6}{|l|}{ Weight loss } \\
\hline $5.0-9.9 \%$ & 210 & 3.8 & 852 & 2.2 & 1.6 (I.4 to 1.8$)$ \\
\hline$\geq 10 \%$ & 351 & 6.4 & 678 & 1.8 & $2.9(2.6$ to 3.1$)$ \\
\hline Abdominal pain & 1629 & 29.7 & 3121 & 8.1 & 3.5 (3.3 to 3.7 ) \\
\hline \multicolumn{6}{|l|}{ Investigations } \\
\hline $\begin{array}{l}\text { Haemoglobin < } 12.0 \\
\mathrm{~g} / \mathrm{dl}\end{array}$ & 1424 & 26.0 & 1803 & 4.7 & $4.4(4.2$ to 4.6$)$ \\
\hline $\begin{array}{l}\text { Mean red cell volume } \\
<80 \mathrm{fl}\end{array}$ & 363 & 6.6 & 923 & 2.4 & $2.8(2.4$ to 3.1$)$ \\
\hline
\end{tabular}

\section{Diagnoses and risk factors}

\begin{tabular}{lccccc}
\hline $\begin{array}{l}\text { Irritable bowel } \\
\text { syndrome }\end{array}$ & 135 & 2.5 & 325 & 0.8 & $2.4(2.1$ to 2.8$)$ \\
\hline Diabetes & 626 & 11.4 & 3679 & 9.6 & $1.2(1.1$ to 1.3$)$ \\
\hline Obesity & 510 & 9.3 & 3510 & 9.2 & $1.0(0.93$ to 1.1$)$
\end{tabular}

Note: the positive likelihood ratio is the likelihood of having a feature when one is a case, divided by the likelihood of having the feature when one is a control. 
Table 2: Independent associations between clinical features and colorectal cancer in the final multivariable conditional logistic regression model.

\section{Clinical feature}

\section{Odds ratio (confidence interval)}

\section{Symptoms}

Rectal bleeding

20 (17 to 23$)$

Change in bowel habit

14 (12 to 17)

Abdominal pain

3.9 (3.6 to 4.3$)$

Diarrhoea

2.4 (2.I to 2.7$)$

Constipation

2.1 ( 1.9 to 2.3$)$

Weight loss

$5.0-9.9 \%$

$1.2(0.99$ to 1.5$)$

$\geq 10 \%$

$2.5(2.1$ to 3.0$)$

\section{Investigations}

Haemoglobin $(g / d l)$

\begin{tabular}{lcc}
\hline & $12.0-12.9$ & $1.7(1.5$ to 1.9$)$ \\
\cline { 2 - 3 } & $11.0-11.9$ & $2.8(2.4$ to 3.2$)$ \\
\cline { 2 - 3 } & $10.0-10.9(4.8$ to 7.2$)$ \\
\hline Mean red cell volume $<80 \mathrm{fl}$ & $9.0-9.9$ & $9.3(7.1$ to 12$)$ \\
\hline
\end{tabular}

Note: associations adjusted for each other; all features have $P<0.001$. 


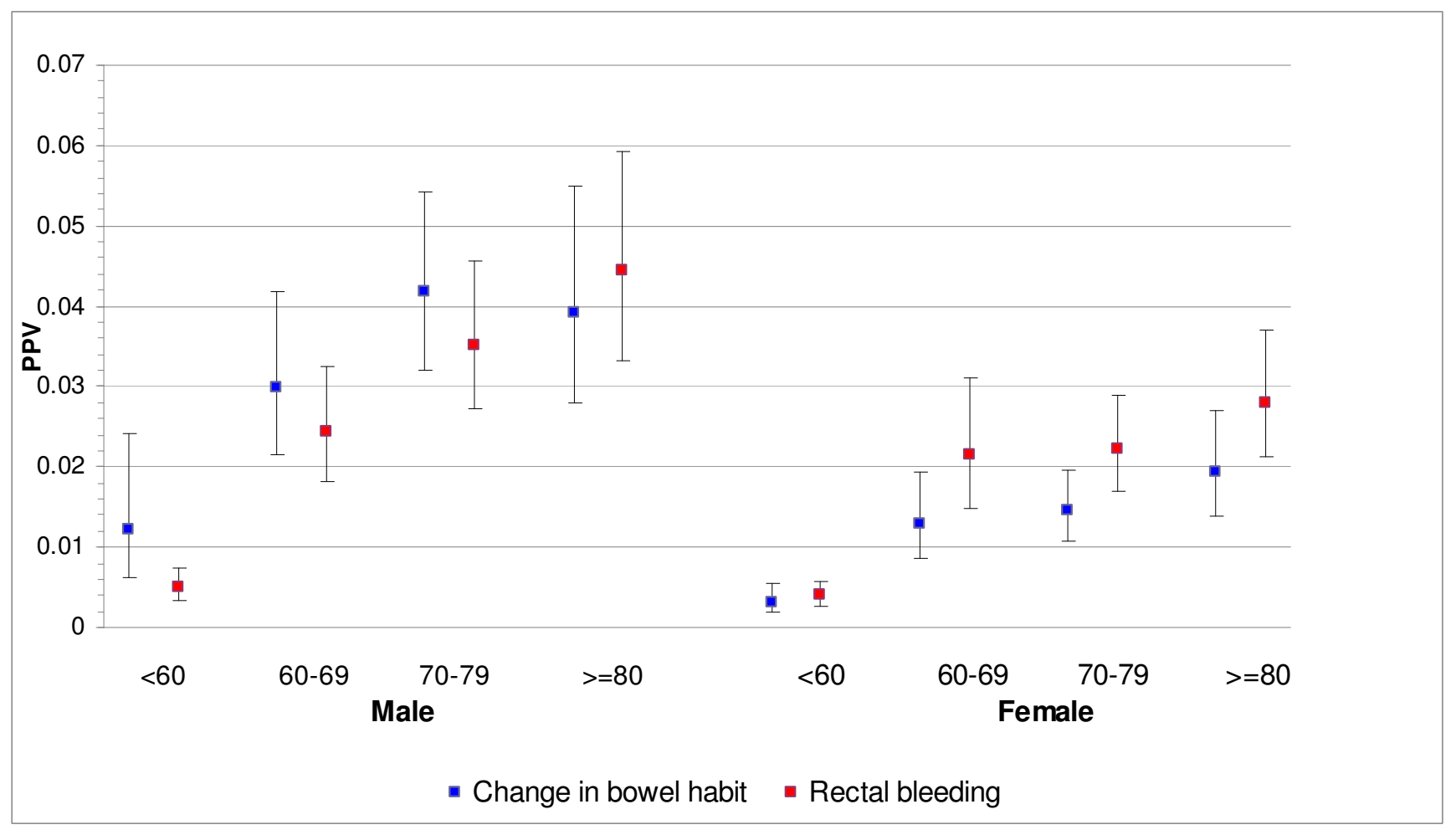

Figure I

Positive predictive values (PPVs) for rectal bleeding and change in bowel habit by age and sex.

\section{Strengths and weaknesses}

This is the largest primary care study to examine all colorectal cancer symptoms. Its size has allowed estimates of PPVs for relatively small age bands in either sex, and with reasonably narrow confidence intervals. Furthermore, the THIN database is representative of the UK as a whole, so our results should be generalisable. However, there are weaknesses too. We could not confirm cancer diagnoses, although it is unlikely that such an important diagnosis would have been entered erroneously particularly often. We also could not examine histology or staging, as these are only rarely recorded on primary care systems. The study relied upon good recording of symptoms. This problem is not quite as important as it appears, as underrecording of symptoms occurring proportionately in both cases and controls would not alter the likelihood ratios. Only if under-recording was especially prevalent in one group would a bias arise. It is impossible to know whether cases or controls would be more prone to under-recording. However, the PPVs are very similar to those derived from paper records [15] (these may of course also suffer from differential recoding of symptoms) and to the two previous studies using electronic records $[13,14]$. One further limitation was the study design: by matching for age and sex, we could not examine these directly. Even so, the dataset was large enough to allow age-sex stratified analyses and estimation of PPVs.

\section{Comparison with previous literature}

Only three papers have used primary care data to estimate risks of colorectal cancer across the ages and between the sexes, although none with the size or precision of this one. The first examined GP records directly and showed an approximate tripling of PPV for rectal bleeding for those aged over 70 compared with those aged 40 to 69 years [15]. Two studies using electronic primary care records reported a rise in the PPV for rectal bleeding across 10-year age bands. This was also seen in the study reported here.

There is much less previous literature for other symptoms: one study gives similar figures for change in bowel habit [14], and the other again showed an approximate tripling of PPV for constipation, diarrhoea and abdominal pain between patients aged 40 to 69 years and those aged over 70 [15].

\section{Relevance of the findings}

It is important to use primary care data to provide evidence for primary care decisions such as when to refer for investigation. Current referral guidelines essentially ignore age (other than giving a minimum age for referral) 


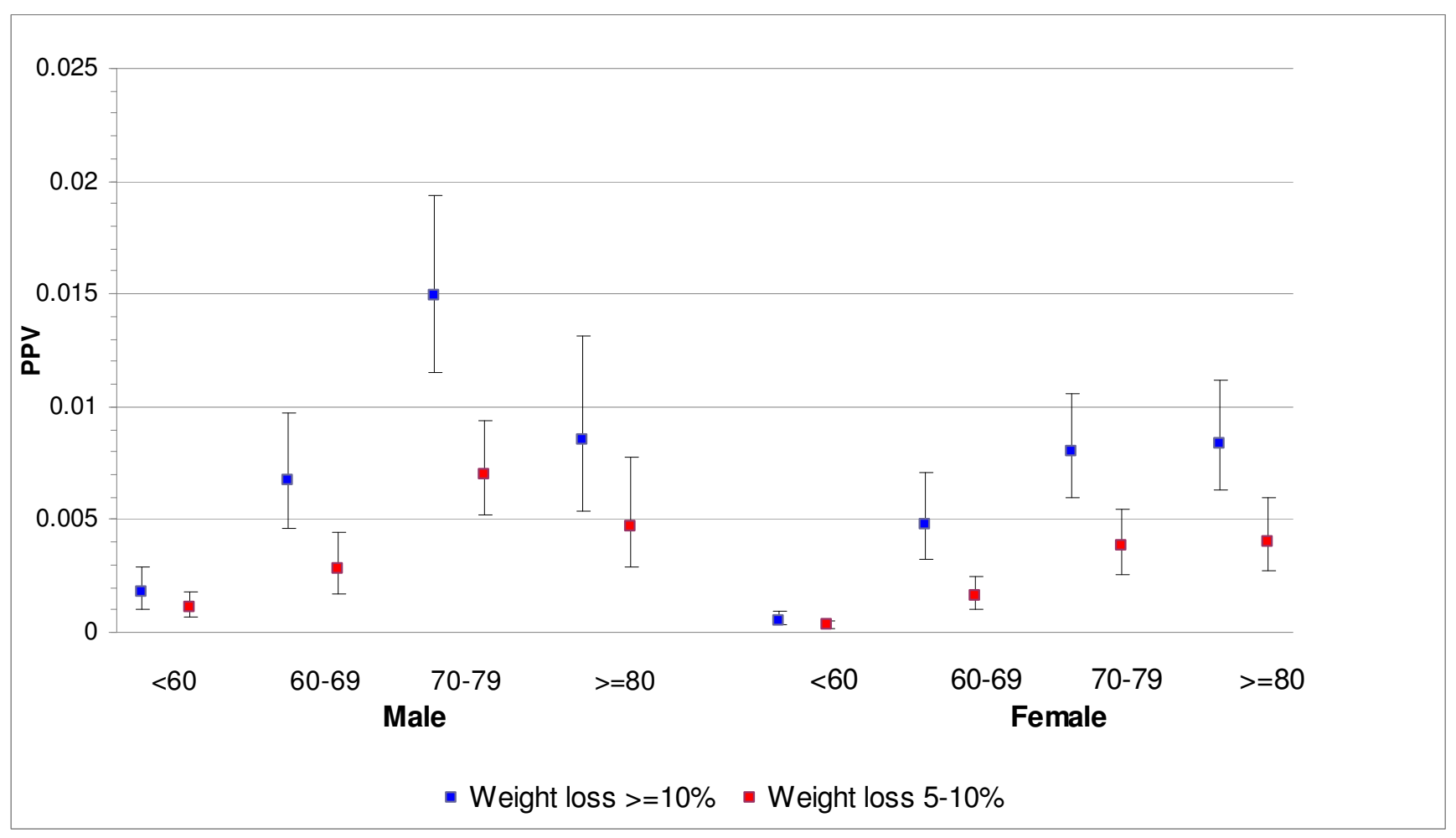

\section{Figure 2}

PPVs for weight loss by age and sex.

and sex (except giving a different threshold of haemoglobin for referral). As the incidence of cancer rises steeply with age, being 16 times higher in the oldest male age group and 13 times higher in the oldest female group when compared with the youngest groups, PPVs could have been expected to differ by as much. They do not, as the likelihood ratios fell with age. This presumably reflects the increasing prevalence of benign causes of colorectal cancer symptoms with age.

Two groups of symptoms emerge from the results. The highest PPVs are for rectal bleeding and change in bowel habit. For men over 60 years, rectal bleeding PPVs ranged from $2.4 \%$ to $4.5 \%$; most would agree these figures are high enough to warrant investigation. For women, the figures were lower, but still in the $2 \%$ to $3 \%$ range. Change in bowel habit is less simple: GPs contributing to THIN must have been using this term very differently from the separate terms of constipation and diarrhoea, in that the PPVs for change in bowel habit were considerably higher. We cannot know what features led GPs to write change in bowel habit in the notes in preference to the specific motility symptoms, however, from our results it is clear that they were identifying a riskier feature, and one that warrants investigation.
In contrast, the PPVs for constipation, diarrhoea, abdominal pain and loss of weight were all below 1.5\%, confirming that they are low-risk symptoms, at any age and in either sex. Indeed, this is the first study to show that the risk of colorectal cancer increases with increasing weight loss. This is no surprise (and is a testament to the quality of THIN data). However, these four symptoms are not 'norisk' symptoms. This creates a problem for design of referral strategies. The high-risk symptoms of rectal bleeding and change in bowel habit were only recorded in $15.6 \%$ and $11.2 \%$ of cases, respectively. Even allowing for possible under-recording, it is highly likely that only a minority of patients with colorectal cancer have a high-risk symptom. The majority, with only a low-risk symptom, could have their diagnosis expedited in a number of different ways. Firstly, scoring systems such as the CAPER score may refine the risk in such patients [21]. Secondly, it is possible that biomarkers may be identified with adequate performance characteristics for use in such a population. Thirdly, early work suggests that measurement of rectal DNA may allow patients at high risk to be selected for investigation [22]. Without one of these initiatives, or a combination of them, patients with a low-risk symptom will continue to be at risk of delayed diagnosis, and possible emergency presentation [23]. 


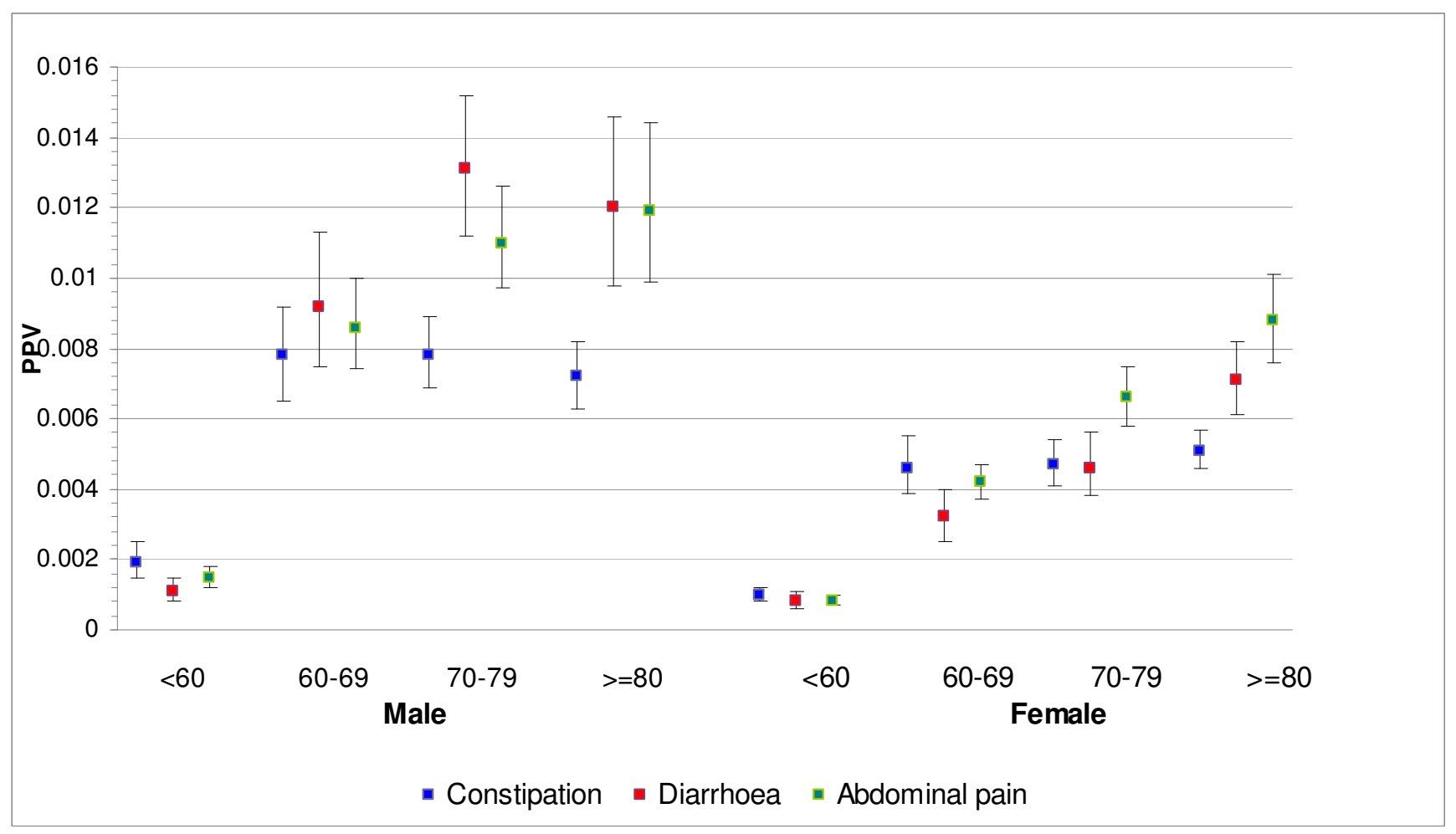

Figure 3

PPVs for constipation, diarrhoea and abdominal pain by age and sex.

\section{Conclusion}

Our results generally support the National Institute for Clinical Excellence referral guidance with respect to symptoms. This is in contrast to the guidance for anaemia, with an unacceptably high PPV at the current threshold recommended for referral [17]. The choice of 60 as a starting age is supported by our findings. Colorectal cancer can occur in younger age groups, but the risk with particular symptoms is very low [24]. Our findings strengthen the view that rectal bleeding carries a high enough risk to warrant investigation irrespective of other symptoms. Current guidance requires persistence of bleeding for 6 weeks, or accompanying diarrhoea [11]. In our opinion, these additional requirements are unnecessary given no study has reported a risk below 2\% for rectal bleeding per se. Even so, there remains a major gap within current guidance: the patient with the low-risk, but not no-risk, symptom. This is important, and suggests a direction for research efforts aimed at reducing mortality from colorectal cancer.

\section{Abbreviations}

FOB: faecal occult blood; GP: general practitioner; GPRD: General Practice Research Database; PPV: positive predictive value; THIN: The Health Improvement Network

\section{Competing interests}

The authors declare that they have no competing interests.

\section{Authors' contributions}

RL constructed the database and performed the analyses guided by WH and TM. All six authors contributed to the design and supervision of the study, and all have read and approved the manuscript. The first draft and revisions were written by $\mathrm{WH}$, incorporating suggestions from the other authors throughout.

\section{Acknowledgements}

We wish to thank THIN staff, especially Mary Thompson, for their help and diligence. The study was funded by the Bobby Moore Fund for Cancer Research UK.

\section{References}

I. Office for National Statistics: Cancer statistics registrations: registrations of cancer diagnosed in 2004, England. Series MBI, No 35. London 2007.

2. Gatta G, Ciccolallo L, Capocaccia R, Coleman MP, Hakulinen T, Moller H, Berrino F: Differences in colorectal cancer survival between European and US populations: the importance of sub-site and morphology. Eur J Cancer 2003, 39:22 14-2222.

3. Mitchell E, Macdonald S, Campbell NC, Weller D, Macleod U: Influences on pre-hospital delay in the diagnosis of colorectal cancer: a systematic review. BrJ Cancer 2008, 98:60-70.

4. Towler B, Irwig L, Glasziou P, Kewenter J, Weller D, Silagy C: A systematic review of the effects of screening for colorectal can- 
cer using the faecal occult blood test, haemoccult. BM] 1998 , 3 I 7:559-565.

5. UK Colorectal Cancer Screening Pilot Group: Results of the first round of a demonstration pilot of screening for colorectal cancer in the United Kingdom. BMJ 2004, 329:133.

6. Anonymous: Colorectal cancer: not an embarrassing problem. Lancet 2005, 366:521.

7. Weller D, Coleman D, Robertson R, Butler P, Melia J, Campbell C, Parker R, Patnick J, Moss S: The UK colorectal cancer screening pilot: results of the second round of screening in England. $\mathrm{Br}$ J Cancer 2007, 97:160I-1605.

8. Goodyear SN, Stallard AG, Parker R, Williams N, Wong L: Local impact of the English arm of the UK Bowel Cancer Screening Pilot study. BrJ Surg 2008, 95: I I72-1 I 79.

9. Hamilton W: Five misconceptions in cancer diagnosis. $\mathrm{Br} J \mathrm{Gen}$ Pract in press.

10. Jiwa M, Hamilton W: Referral of suspected colorectal cancer: have guidelines made a difference? $\mathrm{Br} J$ Gen Pract 2004, 54:608-610.

11. National Institute for Clinical Excellence: Referral Guidelines for Suspected Cancer. London 2005.

12. Jones $R$, Rubin $G$, Hungin $P$ : Is the two week rule for cancer referrals working? BM/ 200I, 322:I555-I556.

13. Jones R, Latinovic R, Charlton J, Gulliford MC: Alarm symptoms in early diagnosis of cancer in primary care: cohort study using General Practice Research Database. BMJ 2007, 334(7602): 1040.

14. Lawrenson R, Logle J, Marks C: Risk of colorectal cancer in general practice patients presenting with rectal bleeding, change in bowel habit or anaemia. Eur J Cancer Care 2006, | 5:267-27|.

15. Hamilton $W$, Round A, Sharp D, Peters $T$ : Clinical features of colorectal cancer before diagnosis: a population-based casecontrol study. Br J Cancer 2005, 93:399-405.

16. du Toit J, Hamilton W, Barraclough K: Risk in primary care of colorectal cancer from new onset rectal bleeding: 10 year prospective study. BMJ 2006, 333:69-70.

17. Hamilton W, Lancashire R, Sharp D, Peters TJ, Cheng K, Marshall T: The importance of anaemia in diagnosing colorectal cancer: a case-control study using electronic primary care records. Br J Cancer 2008, 98:323-327.

18. Curless R, French JM, Williams GV, James OF: Colorectal carcinoma: do elderly patients present differently? Age Ageing 1994, 23:102-107.

19. Knottnerus JA: The Evidence Base of Clinical Diagnosis London: BMJ Books; 2002

20. Incidence Statistics [http://info.cancerresearchuk.org/cancer stats/types/bowel/incidence/]

21. Hamilton W: Derivation of a score for identifying colorectal cancer in primary care. Gut 2007, 56(Suppl 2):A49.

22. Loktionov A: Cell exfoliation in the human colon: Myth, reality and implications for colorectal cancer screening. Int J Cancer 2007, I 20:228I-2289.

23. Cleary J, Peters TJ, Sharp D, Hamilton W: Clinical features of colorectal cancer before emergency presentation: a population-based case-control study. Fam Pract 2007, 24:3-6.

24. Hamilton W: Colorectal cancer in the young. Am J Surg 2005, 189:504.

\section{Pre-publication history}

The pre-publication history for this paper can be accessed here:

http://www.biomedcentral.com/1741-7015/7/17/prepub Publish with Biomed Central and every
scientist can read your work free of charge

"BioMed Central will be the most significant development for disseminating the results of biomedical research in our lifetime. "

Sir Paul Nurse, Cancer Research UK

Your research papers will be:

- available free of charge to the entire biomedical community

- peer reviewed and published immediately upon acceptance

- cited in PubMed and archived on PubMed Central

- yours - you keep the copyright

Submit your manuscript here:

http://www.biomedcentral.com/info/publishing_adv.asp
BioMedcentral 